\section{A saúde das crianças no mundo e no Brasil}

\section{Child health around the world and in Brazil}

Malaquias Batista Filho 1

Rachel de Sá Barreto Luna Callou Cruz 2
${ }^{1}$ Instituto de Medicina Integral Prof. Fernando Figueira. Recife, PE, Brasil. E-mail: malaquias.imip@gmail.com

2 Programa de Pós-graduação em Saúde Materno Infantil. Instituto de Medicina Integral Prof. Fernando Figueira. Recife, PE, Brasil.

\begin{abstract}
The authors examined the recent report by the WHO (World Health Organization), United Nations Children's Fund (UNICEF), and World Bankintergenerational group for the period between 1990 and 2015, regarding international commitments and goals relating to the reduction of mortality in children aged under five years. This is an historical paper, covering the 25 yearsof the Universal Declaration of the Rights of the Child and Adolescent, the results of international accords signed by heads of state at the New York summit meeting (1990) and the Millennium Goals agreed by 195 countries. The report notes that only 62 countries succeeded in meeting the stipulated objective of reducing mortality by 2/3 (66.7\%) while Brazil achieved a reduction of $73 \%$ before the deadline of the end of 2015. The authors point to the heterogeneity of results obtained in Brazil and around the world,with wide disparities between different geographical regions and variations ranging from $5 \%$ to over $80 \%$. This can be attributed to the huge inequalities in living conditions that still prevail in most countries, including Brazil. Most important, however, is the fact that the successes achieved are without parallel in the nosographic history of humanity.
\end{abstract}

Key words Child health, Infant mortality, Goals, United Nations

\section{Resumo}

Os autores analisam o recente relatório do grupo intergeracional OMS (World Health Organization WHO), Fundo das Nações Unidas para a Infância (UNICEF), Banco Mundial, consolidado pelas Nações Unidas, cobrindo o período 1990/2015, em relação aos compromissos e metas internacionais para a redução da mortalidade de menores de cinco anos no mundo. Trata-se de um "paper" histórico, correspondendo aos 25 anos da Declaração Universal dos Direitos das Crianças e dos Adolescentes, aos resultados de acordos internacionais firmados pelos chefes de estado na Reunião de Cúpula de Nova York (1990) e, em sequência, às Metas do Milênio, consensuadas por 195 países. $O$ relatório destaca que apenas 62 países conseguiram cumprir o objetivo estipulado de reduzir a mortalidade em 2/3 (66,7\%) sendo que o Brasil alcançou uma redução de $73 \%$ antes do prazo estabelecido, final de 2015. Os autores ressaltam a heterogeneidade dos resultados obtidos no Brasil e no mundo, com uma grande diferença entre os espaços geográficos, com variações que se deslocam entre 5\% a mais de $80 \%$, atribuindo-se essas grandes diferenças às desigualdades de condições de vida que ainda prevalecem na maior parte dos paises, inclusive no Brasil. O mais importante é que os êxitos alcançados são singulares na história nosográfica da humanidade.

Palavras-chave Saúde da criança, Mortalidade infantil, Metas, Nações Unidas 


\section{Introdução}

O processo saúde/doença de um povo não é um tema restrito aos profissionais da área: médicos, enfermeiros, psicólogos, fisioterapeutas, nutricionistas, farmacêuticos, engenheiros sanitários e dezenas e dezenas de outros agentes incorporados ao complexo de cuidados que operam entre a higidez e a doença. Da mesma forma, o dualismo guerra e paz não é um espaço a ser decidido por militares das três armas (exército, marinha e aeronáutica) e seus escalões de hierarquia e especializações. Um e outro campo saúde e doença, guerra e paz - são processos geopolíticos em sua concepção, formulação e gestão, de modo que os eventos envolvidos, como produtos históricos, abrangem causas e efeitos como fisiopatologia do corpo social em seu conjunto. Ou seja, com seus componentes econômicos, políticos, sociais, ambientais, culturais, suas condutas éticas, suas diferenças de protagonismo individual e grupal, suas experiências ainda preliminares de contabilizar a sustentabilidade como um compromisso crucial com o futuro. Ainda que tais componentes possam ser observados como variáveis discretas, numa visão cartesiana simplificada para decompor a realidade em partes, de fato são processos encadeados, interativos, articulados em sucessivos feed-backs. ${ }^{1}$

Esta perspectiva conceitual torna-se, na atualidade, o próprio fundamento doutrinário do desenvolvimento humano. Ainda que se possa desagregar ou setorizar, para a aplicação de indicadores específicos, os vários processos que acompanham o desenvolvimento humano, na realidade a saúde, com sua especificidade descritiva e seus instrumentos próprios de ação e avaliação, constitui um campo unificado de respostas de um todo solidário - e não de um setor solitário e corporativo. É nesta visualização que deve ser entendido o mais recente relatório das Nações Unidas sobre a saúde das crianças no mundo e, numa perspectiva nacional, o caso do Brasil. No mundo, em 25 anos (1990-2015) a mortalidade infantil caiu pela metade. No entanto, em apenas 52 nações, ou seja, menos de 1/3 dos 195 países avaliados, chegou-se à redução proposta e acordada nos objetivos de Desenvolvimento do Milênio, segundo estudo publicado no Lancet. ${ }^{2}$ Em números absolutos, em escala mundial, a contabilidade epidemiológica medida em termos de mortalidade declinou de 12,7 milhões de mortes anuais para a estimativa de 5,9 milhões em 2015, segundo o estudo conjunto da Organização Mundial da Saúde/ Fundo das Nações Unidas para a Infância (OMS/UNICEF).3,4 Descrito de outra forma: no início da década de 1990, morriam, diariamente,
35.000 crianças, enquanto agora morrem 16.000 a cada 24 horas. E isto poderia baixar, seguramente, para 8000 ou 4000 mortes, dentro de 10 ou 15 anos. É um resultado importantíssimo, desenhando uma perspectiva animadora e ímpar para toda a trajetória da humanidade. 5

No entanto, computadas em seu conjunto, as estatísticas deixam de revelar o variado mosaico que ainda configura a cartografia da mortalidade de crianças em escala mundial. Assim, os países mais adiantados e mesmo nações que não participam do ranking mais competitivo da economia globalizada já apresentam taxas de mortalidade abaixo de 5 por 1000 nascidos vivos, enquanto outros ainda têm resultados que remontam à metade do século passado. Ou seja, 1950, quando foram documentadas as evidências de uma revolução demográfica e sanitária (a transição epidemiológica) que redefine uma nova fase na história nosográfica da humanidade, demarcando um outro cenário de morbimortalidade, dentro de uma moldura inédita de condições e estilos de vida. 6,7

É curioso e ao mesmo tempo instigante perceber que o Brasil faz parte do restrito grupo de nações que cumpriram o "dever de casa", respondendo ao desafio das Metas do Milênio. Assim, a mortalidade de nossas crianças foi reduzida em $73 \%$, um resultado bem acima da marca de $2 / 3$ estabelecida nas Metas do Milênio 2000, como continuidade e atualização do objetivo decenal (1990-2000) firmado na Reunião de Cúpula de Nova York. ${ }^{8}$

No entanto, refletindo em escala nacional o próprio retrato da saúde das crianças no mundo, como se fosse a imagem de um espelho, no Brasil mais de 1000 dos 5500 municípios, portanto, mais de $18 \%$, tinham mortalidade de menores de cinco anos abaixo de 5 por 1000 crianças nascidas vivas, praticamente simulando um grupo seleto de nações mais desenvolvidas, como os países escandinavos ou ainda a Bélgica, a Holanda, a Suíça, a Alemanha e, excepcionalmente, a ainda subdesenvolvida Cuba, cujos índices recaem nos patamares desse alfa de 5 por mil. Já no último quartil de uma escala crescente situam-se municípios com estatísticas comparáveis aos países mais atrasados da África, com 80 e mais mortes para 1000 nascidos vivos. É um contraste que se mantém há muito tempo. ${ }^{9}$

É pertinente e oportuno destacar que o informe intergeracional das Nações Unidas, elaborado pelo UNICEF, OMS e Banco Mundial ${ }^{3}$ documenta um período histórico de marcante significação para a humanidade: são os 25 anos da Declaração dos Direitos das Crianças e dos Adolescentes, formalizada em 1990,10 e da realização da Assembleia das 
Nações Unidas sobre saúde, nutrição, sobrevivência e desenvolvimento das crianças, definindo um programa de metas e estratégias para a década 1990/2000, seguindo-se dos 15 anos das metas do Milênio. Trata-se, de certa maneira, de uma experiência de governança mundial, onde os direitos civis de cidadania devem ser respaldados com ações e resultados concretos, como estes divulgados no relatório das Nações Unidas. É, por assim dizer, uma prestação pública de contas sobre a situação de saúde das crianças no mundo, evidenciando os progressos alcançados face aos compromissos assumidos. E já agora se vislumbra um novo horizonte: além dos avanços e insucessos parciais, já se consolida a expectativa de novo compromissos dos povos do mundo sobre a questão crucial da sustentabilidade. 11 Não basta melhorar o desempenho temporal da evolução, é necessário assegurar que o futuro seja sustentável. E isto já é, historicamente, uma conquista conceitual e pragmática na formulação e gestão da saúde de crianças e adolescentes, o que inclui suas famílias, a busca pela equidade e a preservação do meio ambiente saudável em sua dimensão física, biótica e social. 12

Em termos de distribuição geográfica, um outro fato auspicioso foi a constatação de que, na África Subsaariana, (na realidade, quase toda a África, com exceção de seus países da costa Mediterrânea) onde eram e ainda são registradas as estatísticas mais desfavoráveis do obituário entre as crianças de todo o mundo, a redução anual da mortalidade, que era de $1,5 \%$ na década de 1990 , passou a decair $4,1 \%$ nos últimos 15 anos. 3 A propósito do contexto, em

\section{Referências}

1. Almeida Filho N. O que é saúde? Rio de Janeiro: Editora Fiocruz; 2011. 160 p. (Coleção temas em saúde).

2. Alkema L, Fengqing Chao, Danzhen You, Jon Pedersen, Cheryl C Sawyer. National, regional, and global sex ratios of infant, child, and under-5 mortality and identification of countries with outlying ratios: a systematic assessment. Lancet Global Health. 2014; 2 (9): 521-30.

3. UNICEF (Fundo das Nações Unidas para a Infância). Levels \& Trends in Child Mortality. Report 2015 Estimatives developed by the UN inter-agency group for child mortality estimation. New York: UNICEF/WHO; 2015. [acesso em 7 set 2015]. Disponível em: http://www.childmortality.org/files_v20/download/IGME\% 20Report\%202015_9_3\%20LR\%20Web.pdf

4. UNICEF (Fundo das Nações Unidas para a Infância). Situação Mundial da Infância 2015: resumo executivo. Reimagine o futuro - inovação para cada criança. Brasília (DF): UNICEF; 2015. [acesso em 15 set 2015]. Disponível em: http://www.unicef.org/brazil/pt/SOWC2015Resumo Executivo.pdf relatório mais recente, o Banco Mundial assinala que, entre 2012 e 2015 , a população mundial em condições de pobreza (renda de 1,25 dólares por dia) caiu de 12,3\% (102 milhões) para 9,6\% (702.100.000). É um valor, também histórico, permitindo já a elaboração de estratégias para que em 2030, o mundo possa chegar ao fim da pobreza extrema e se empenhar na construção da prosperidade partilhada. ${ }^{13}$

Diante destas mudanças quantitativas de desfechos, é evidente que se estabeleçam mudanças simultâneas de processos, não apenas no nível proximal de causas mais diretas, como nos níveis de relações intermediárias e estruturais que conformam a organização e as funções da sociedade. No mundo e no Brasil, os grandes diferenciais das estatísticas de mortalidade das crianças são manifestações bem ilustrativas das disparidades socioeconômicas e ambientais que ainda dificultam o pleno acesso e uso dos meios de promoção, proteção e recuperação da saúde.

Ainda há um grande espaço de respostas positivas em que medidas setoriais podem ser efetivas, mas existe um enorme diferencial de desigualdades que só podem ser resolvidas com a superação das assimetrias inaceitáveis que contrastam as nações, os estratos sociais e as unidades familiares onde as crianças estão inseridas. Isto vale para o Brasil e para o mundo e oportuniza a observação de que a saúde das crianças, por sua importância para o presente e para o futuro, ganha o status de questão transtemporal e de governabilidade crescentemente universal. É um problema de todos.

5. Lawn JE, Blencowe H, Oza S, You D, Lee AC, Waiswa $\mathrm{P}$, Lalli M, Bhutta Z, Barros AJ, Christian P, Mathers C, Cousens SN; Lancet Every Newborn Study Group. Every Newborn: Progress, priorities and potential beyond survival. Lancet. 2014; 384 (9938): 189-205.

6. Friederiksen, H. Feedbacks: economic and demographic transition. Science. 1969; 166 (3907): 837-47.

7. Popkin BM. Nutritional patterns and transitions. Popul Dev Rev. 1993; 9 (1): 138-57.

8. UNICEF (Fundo das Nações Unidas para a Infância). Estratégia para Melhorar a Nutrição de Crianças e Mulheres nos Países em Desenvolvimento. New York: UNICEF; 1990.

9. Batista Filho M. Brasil: o multipaís. Revista do IMIP. 1991; 5 (1): 1-2.

10. Brasil. Lei Federal no 8069, de 13 de julho de 1990. Estatuto da Criança e do Adolescente. Brasília, DF; [DOU 16 jul 1990]. 
11. Amartya S. Desenvolvimento como Liberdade. São Paulo: Companhia das Letras; 1999. cap. 3.

12. Batista Filho M, Batista LV. Transição alimentar/ nutricional ou mutação antropológica? Cienc Cult. 2010; 62 (4): 26-30.

13. Cruz M, Foster J, Quillin B, Schellekens P. WBG (World Bank Group). Policy Research Note - Ending Extreme Poverty and Sharing Prosperity: Progress and Policies. WBG; 2015. [Acesso em 06 out 2015]. Disponível em: http://www.worldbank.org/en/research/brief/policyresearch-note-03-ending-extreme-poverty-and-sharingprosperity-progress-and-policies

Recebido em 1 de setembro de 2015

Versão final apresentada em 10 de setembro de 2015

Aprovado em 1 de outubro de 2015 